\title{
Neurotensin receptors: a new marker for human ductal pancreatic adenocarcinoma
}

\author{
J C Reubi, B Waser, H Friess, M Büchler, J Laissue
}

\begin{abstract}
BackgroundlAims-New imaging possibilities for early diagnosis of the devastating exocrine pancreatic adenocarcinomas would be highly welcome. Recently, pancreatic neuroendocrine tumours have been successfully visualised in vivo on the basis of their high density of receptors for the regulatory peptide somatostatin. Unfortunately, exocrine pancreatic tumours do not express sufficient amounts of somatostatin receptors. Therefore overexpression of other regulatory peptide receptors in these tumours needs to be found.

Methods-Receptors for the regulatory peptide neurotensin were evaluated in vitro by receptor autoradiography in 24 ductal pancreatic adenocarcinomas, 20 endocrine pancreatic cancers, 18 cases of chronic pancreatitis, and 10 normal pancreatic glands.
\end{abstract}

Results-Some $75 \%$ of all ductal pancreatic adenocarcinomas, most of them differentiated, were neurotensin receptor positive, whereas endocrine pancreatic cancers did not express neurotensin receptors. No neurotensin receptors were found in chronic pancreatitis or normal pancreatic tissues, including pancreatic acini, ducts, and islets.

Conclusions-The selective and high expression of neurotensin receptors in ductal pancreatic adenocarcinomas could form the molecular basis for potential clinical applications, such as in vivo neurotensin receptor scintigraphy for early tumour diagnosis, radiotherapy with radiolabelled neurotensin analogues, and chemotherapy with neurotensin receptor antagonists.

(Gut 1998;42:546-550)

Keywords: neurotensin receptors; ductal pancreatic carcinomas; chronic pancreatitis; endocrine pancreatic tumours; in vivo scintigraphy; regulatory peptides

Carcinoma of the exocrine pancreas is the fifth largest cause of death from cancer in western countries. ${ }^{12}$ It grows extremely rapidly, and early diagnosis allowing therapeutic surgical resection is rarely possible. ${ }^{12}$ No alternative medical therapy is available. Therefore a non-invasive method of early diagnosis of this type of cancer would be extremely useful.

In the last few years, a new in vivo diagnostic method has been developed and widely used with great success to localise neuroendocrine pancreatic tumours, ${ }^{3-5}$ based on the specific binding in vivo of the somatostatin analogue ${ }^{111}$ In] pentetreotide (Octreoscan) to sst2 somatostatin receptors expressed in high density in neuroendocrine cancer. ${ }^{67}$ Unfortunately, this method cannot be used for the diagnosis of exocrine pancreatic cancers since they do not express sufficient amounts of these somatostatin receptors. ${ }^{8-10}$ Therefore it is worth loooking for receptors for other small regulatory peptides that may be expressed in high density and with high incidence in exocrine pancreatic adenocarcinomas. ${ }^{10}$ One candidate peptide of interest is neurotensin, a 13 amino acid peptide found in brain and gut. Neurotensin has, among other actions, a growth regulatory function in colon and pancreatic cell lines. ${ }^{11}{ }^{12}$ In the present study, we evaluated neurotensin receptor expression in vitro in primary human pancreatic adenocarcinomas, and compared the results with its expression in normal human pancreas and in chronic pancreatitis, as well as in endocrine pancreatic tumours, in order to gauge the potential diagnostic value of in vivo neurotensin receptor scintigraphy in pancreatic adenocarcinomas.

\section{Methods}

Aliquots of surgically resected tumours or of biopsy specimens submitted for diagnostic histopathology were collected. A total of 24 ductal

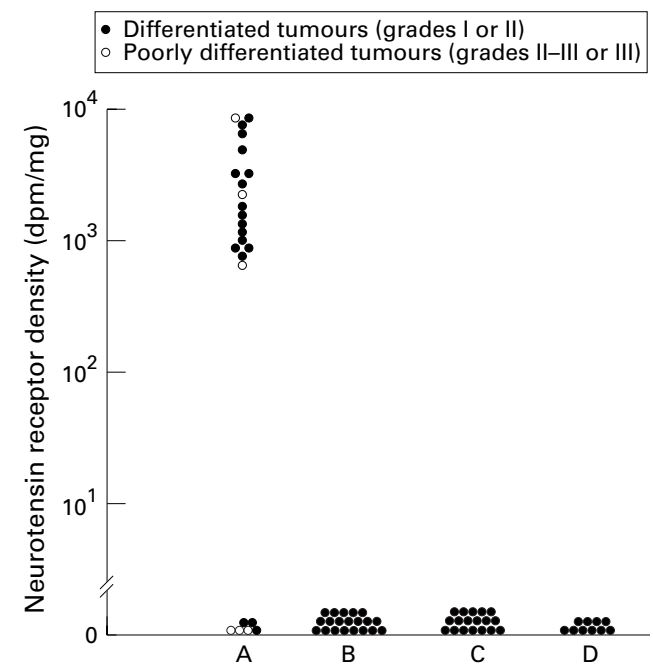

Figure 1 Density of neurotensin receptors in various human pancreatic tissues. $A$, ductal pancreatic adenocarcinomas $(n=24) ; 18$ are differentiated tumours (grade I or II), and six are poorly differentiated tumours (grade II-III or III). B, endocrine pancreatic cancers ( $n=$ 20). $C$, chronic pancreatitis $(n=18)$. $D$, normal pancreas $(n=10)$. In $A$ and $B$, the neurotensin receptor content of each tumour (dpm/mg tissue) was measured by quantitative in vitro receptor autoradiography. ${ }^{13}$ In $C$ and $D$, the pancreatic acini, ducts, and islets were evaluated for their neurotensin receptor content by the same method. 


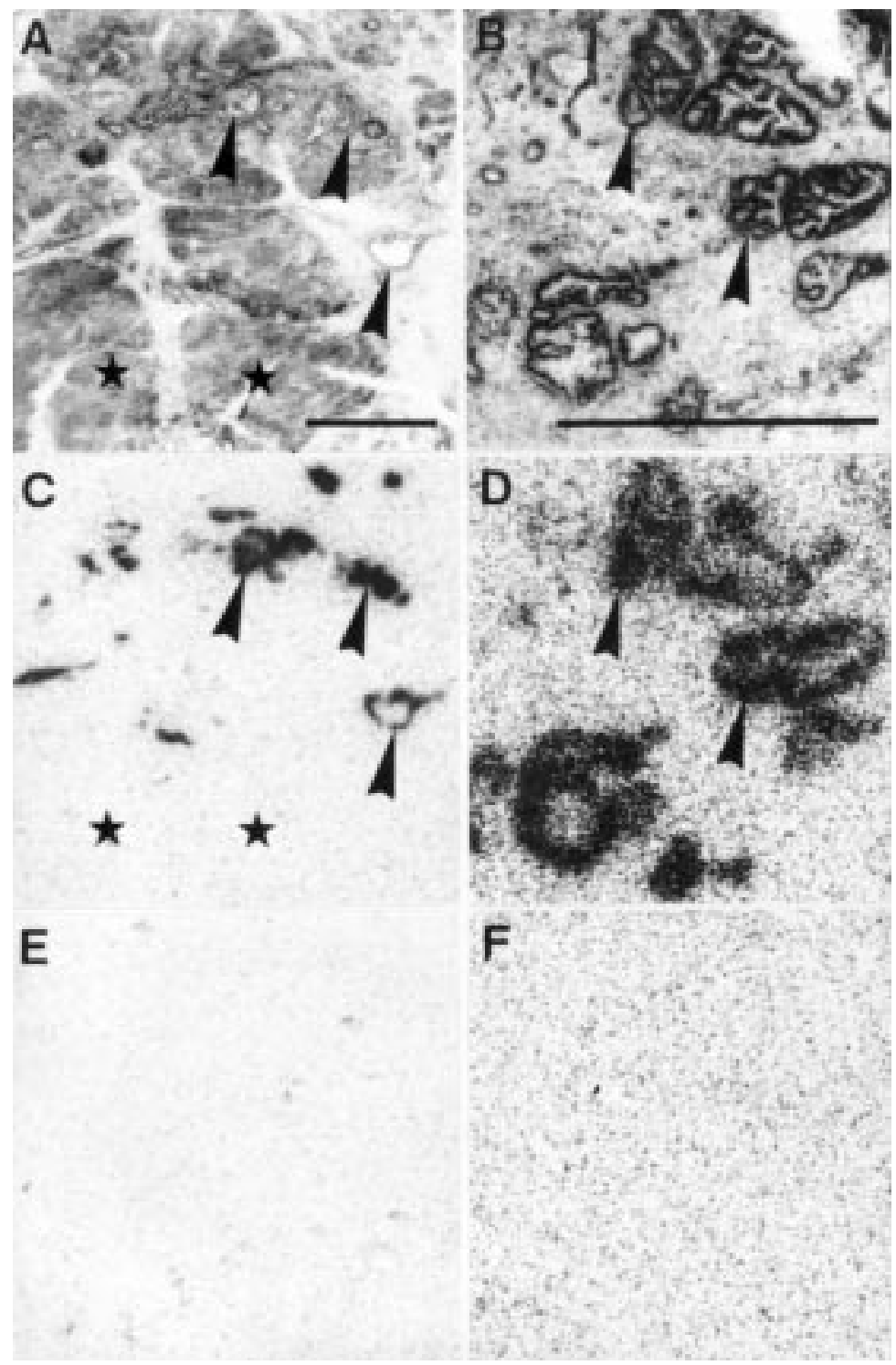

Figure 2 Neurotensin receptors in two well differentiated ductal pancreatic adenocarcinomas. $(A)$ and $(B)$ show the haematoxylin-eosin stained sections representing tumour duct-like structures (arrowheads) surrounded by non-neoplastic pancreatic acini (asterisks). Bars $=1 \mathrm{~mm}$. (C) and (D) show autoradiograms with total binding of

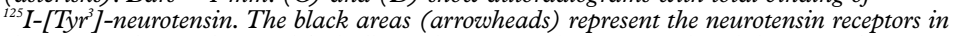
the tumour ducts. The asterisks indicate the receptor-free pancreatic acini. $(E)$ and $(F)$ show autoradiograms with non-specific binding of ${ }^{125} I-\left[T_{y} r^{3}\right]-n e u r o t e n s i n$ (in the presence of $10^{-6} \mathrm{M}$ neurotensin).

pancreatic adenocarcinomas were included in this study. They were obtained from 13 male and 11 female patients, with an age range from 49 to 89 years (mean age 68 years). Eighteen tumours were differentiated (grade I or II), and six were poorly differentiated (grade II-III or III). In addition, samples from 18 patients with chronic pancreatitis, 10 normal pancreatic glands from organ donors, and 20 endocrine pancreatic tumours (including gastrinomas, insulinomas, vipomas, glucagonomas, and non-secreting tumours) were collected.

All tissues were frozen in liquid nitrogen immediately after surgical resection and stored at $-70^{\circ} \mathrm{C}$. Receptor autoradiography was performed on 10 and $20 \mu \mathrm{m}$ thick cryostat (Leitz 1720, Rockleigh, NJ, USA) sections of the tissue samples, mounted on microscope slides, and then stored at $-20^{\circ} \mathrm{C}$ for at least

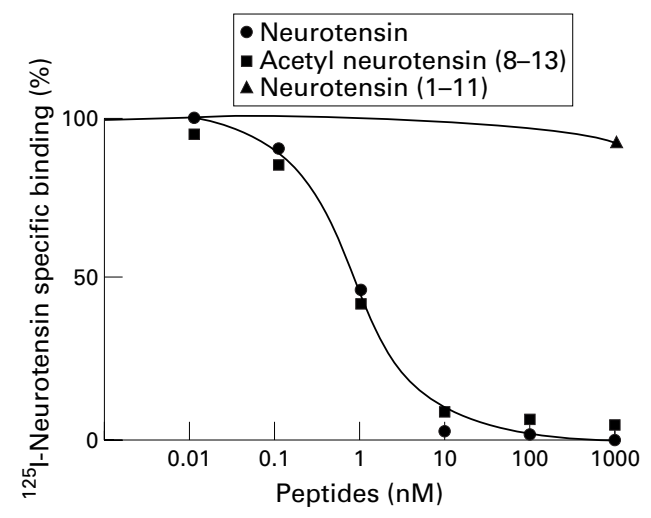

Figure 3 High affinity and specificity of the ${ }^{125} \mathrm{I}-\left[\mathrm{Tyy}^{3}\right]$-neurotensin binding in a displacement experiment. Sections of a ductal pancreatic adenocarcinoma were incubated with ${ }^{125} I-\left[T_{y}{ }^{3}\right]-$-neurotensin and increasing concentrations of unlabelled neurotensin,

acetyl-neurotensin-(8-13), and neurotensin-(1-11). High affinity displacement of the trace is found with neurotensin and acetyl-neurotensin-(8-13), whereas the biologically inactive neurotensin-(1-11) had no effect. Non-specific binding was subtracted from all values.

three days to improve adhesion of the tissue to the slide, as previously described. ${ }^{13}$ Each tissue underwent receptor autoradiographic processing, as described by Moyse et al, ${ }^{14}$ using ${ }^{125} \mathrm{I}-\left[\mathrm{Tyr}^{3}\right]$-neurotensin as radioligand. Neurotensin binding was achieved by incubating the sections with $40000 \mathrm{dpm} / 100 \mu \mathrm{l}$ monoiodo ${ }^{125} \mathrm{I}-\left[\mathrm{Tyr}^{3}\right]$-neurotensin $(2000 \mathrm{Ci} / \mathrm{mmol}$; Anawa, Wangen, Switzerland) in $50 \mathrm{mM}$ Tris/ $\mathrm{HCl}$ buffer, $\mathrm{pH} 7.6$, containing $5 \mathrm{mM} \mathrm{MgCl}$, $0.2 \%$ bovine serum albumin, and $5 \times 10^{-5} \mathrm{M}$ bacitracin at $4^{\circ} \mathrm{C}$ for one hour. Additional sections were incubated in the presence of increasing amounts of non-radioactive neurotensin, acetyl-neurotensin-(8-13), and neurotensin-(1-11), to generate competitive inhibition curves. After incubation, the sections were washed for eight minutes at $4^{\circ} \mathrm{C}$ in four consecutive baths containing $50 \mathrm{mM}$ Tris $/ \mathrm{HCl}$ buffer, $\mathrm{pH}$ 7.6. The sections were then dried under a stream of cold air at $4^{\circ} \mathrm{C}$, apposed to $3 \mathrm{H}$ Hyperfilms (Amersham, Little Chalfont, Bucks, UK), and exposed for seven days to $x$ ray cassettes.

The autoradiograms were quantified using a computer assisted image processing system, as described. ${ }^{13}$ Tissue standards for iodinated compounds (Amersham) were used for this purpose. A tumour was defined as receptor positive when the optical density measured over a tumour area in the total binding section was at least twice that of the non-specific binding section (in the presence of $10^{-6} \mathrm{M}$ neurotensin). In each experiment, rat and human brain tissues, rich in neurotensin receptors, were included as positive controls.

Somatostatin receptor autoradiography for the sst2 subtype was performed on the endocrine pancreatic cancers using ${ }^{125} \mathrm{I}-\left[\mathrm{Tyr}^{3}\right]-$ octreotide as radioligand, as described previously. ${ }^{613}$

\section{Results}

As shown in fig 1,75\% of all human ductal pancreatic adenocarcinomas expressed neurotensin receptors. A considerable variability in 


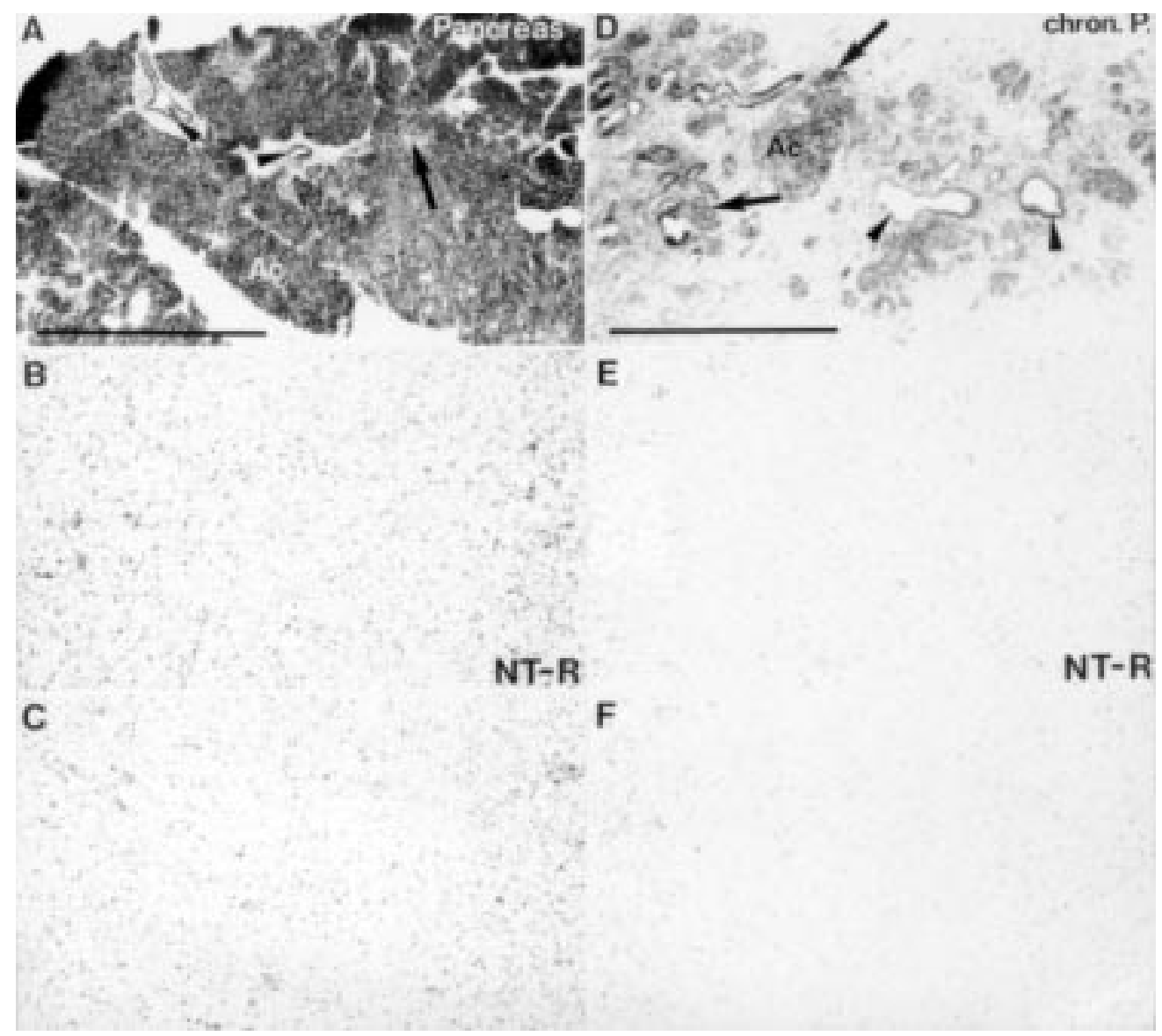

Figure 4 Absence of neurotensin receptors in normal human pancreatic tissue $(A-C)$ and in chronic pancreatitis $(D-F)$. (A), (D) Haematoxylin-eosin stained sections showing pancreatic acini (Ac), pancreatic ducts (arrowheads), and pancreatic islets (arrows). Bars $=1 \mathrm{~mm}$. (B), (E) Autoradiograms showing total binding of ${ }^{125}$ I-[Tyr $\left.{ }^{3}\right]$-neurotensin. (C),

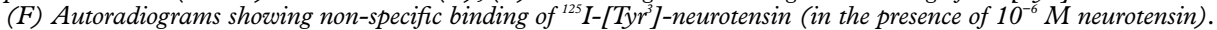

receptor density is observed among individual cases, ranging from a lack of neurotensin receptors to very high amounts peaking at 8000 $\mathrm{dpm} / \mathrm{mg}$ tissue, an observation that is compatible with the polyclonality and morphological variability of neoplasms. We observed neurotensin receptors more often in differentiated than in poorly differentiated tumours: indeed, as many as $83 \%$ of the differentiated adenocarcinomas were receptor positive; in particular, tumours with tubular differentiation were more often positive than solid tumours. Further, several cases displayed a heterogeneous distribution of the neurotensin receptors, even among histopathologically similar tumour areas.

As shown in a characteristic example in fig 2, the neurotensin receptors are exclusively located on tumour cells; the neoplastic duct-like structures are clearly receptor positive, whereas no receptors can be detected in adjacent normal pancreatic ducts, acini, and islets. The binding characteristics of neurotensin receptors correspond to those established previously. ${ }^{114}$ As seen in the displacement curve in fig 3, neurotensin receptors show high affinity binding in the nanomolar range; moreover, the binding is specific, since the biologically active analogue acetyl-neurotensin(8-13) has a similar affinity to that of neurotensin, whereas the biologically inactive neurotensin-(1-11) has no such affinity.
The neurotensin receptors were also evaluated in large samples of normal pancreatic tissue obtained from organ donors as well as in chronic pancreatitis: in these tissues, neither the pancreatic acini and ducts nor the islets expressed these receptors in measurable amounts (figs 1 and 4). Moreover, in a series of endocrine pancreatic tumours, including insulinomas, gastrinomas, glucagonomas, and vipomas, neurotensin receptors were undetectable (fig 1), whereas somatostatin receptors were expressed at high density (fig 5), as reported previously. ${ }^{13}$

\section{Discussion}

The results of the present study show the presence of neurotensin receptors in human ductal pancreatic adenocarcinomas. These findings extend the knowledge of the biology of these adenocarcinomas, by identifying neurotensin as an additional factor of their pathophysiology. Exocrine pancreatic carcinomas not only synthesise and secrete several growth factors, such as epidermal growth factor, and their respective receptors, ${ }^{15}$ but may also be responsive to hormones and regulatory peptides acting at specific membrane bound receptors, often expressed in high density. Neurotensin may play a functional role, since it was shown in pancreatic cell lines to stimulate tumour cell growth. ${ }^{12}$ The presence of a large number of 

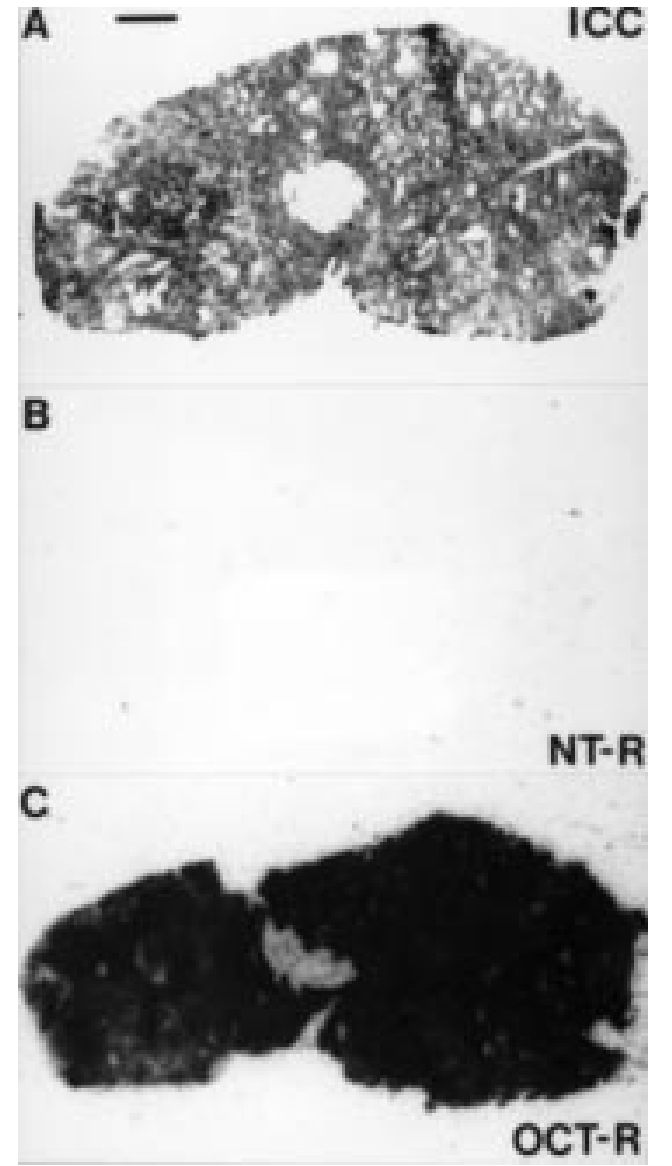

Figure 5 Endocrine pancreatic tumour lacking neurotensin receptors (B) but expressing a high density of somatostatin receptors (C). (A) Haematoxylin-eosin stained section showing the tumour. Bar $=1 \mathrm{~mm}$. (B) Autoradiogram showing total binding of

${ }^{125}$ I-[Tyr $\left.{ }^{3}\right]$-neurotensin. (C) Autoradiogram showing sst2 somatostatin receptors identified by the binding of

${ }_{125}$ I-[Tyr $\left.{ }^{3}\right]$-octreotide (OCT-R). In (B) and (C), non-specific binding was negligible.

high affinity neurotensin receptors in pancreatic adenocarcinomas could therefore contribute significantly to their aggressive growth and the fatal outcome.

The high selectivity of neurotensin receptor expression in ductal pancreatic adenocarcinomas is underlined by the fact that no measurable levels of neurotensin receptors could be found in tissue samples from patients with chronic pancreatitis, a presumptive premalignant condition leading to pancreatic adenocarcinomas. ${ }^{16}$ In contrast, epidermal growth factor receptors are expressed in significant amounts in both chronic pancreatitis and the normal pancreas (J C Reubi, unpublished work). ${ }^{15}$ Because of their overexpression in ductal pancreatic adenocarcinomas and their absence in normal pancreas and chronic pancreatitis, neurotensin receptors can be considered as a marker for most ductal pancreatic adenocarcinomas, an observation with great clinical relevance. ${ }^{1}$ Indeed, simply the demonstration of neurotensin receptors in the pancreas may indicate the presence of an adenocarcinoma in a patient. Neurotensin receptors are also likely to discriminate between malignant exocrine and endocrine pancreatic neoplasms, since the latter are lacking neurotensin receptors. However, the absence of neurotensin receptors from pancreatic tissue does not completely exclude the presence of pancreatic cancer, since a minority of our exocrine tumours were found to be receptor negative in vitro.

The potential direct clinical consequences of the present data are considerable. In analogy to in vivo somatostatin receptor scintigraphy, it may be possible in the future to perform neurotensin receptor scintigraphy for early detection and differential diagnosis of exocrine pancreatic cancer. Three important prerequisites for the success of such a method are fulfilled. (1) High affinity neurotensin receptors are specifically located on the tumour cells in three quarters of the cases. (2) An adequate radiotracer, a small neurotensin hexapeptide analogue linked to $N^{u}$-diethylenetriaminepentaacetic acid (DTPA) which has the property to chelate ${ }^{111} \mathrm{In}$, a routinely used radioisotope in diagnostic nuclear medicine, and which retains high binding affinity, is available. ${ }^{17}$ This neurotensin analogue, like DTPA-octreotide, ${ }^{4}$ is rapidly cleared through the kidneys and virtually not excreted through the biliary and gastrointestinal tracts, ${ }^{17}$ a significant advantage in terms of background activity in the pancreatic area. (3) The neurotensin receptors can be rapidly internalised, together with the bound radioligand, into target cells ${ }^{18}$ : such a mechanism is likely to contribute to the high scintigraphic signal observed during in vivo somatostatin receptor scanning of neuroendocrine tumours. ${ }^{4}$

Finally, neurotensin receptors may serve as a highly specific therapeutic tool, especially in those tumours that express them in abundance. Radiotherapy of tumours with neurotensin analogues linked to a $\beta$-emitting isotope may be envisaged, as shown in preliminary radiotherapeutic studies using radiolabelled somatostatin analogues in somatostatin receptor expressing tumours. ${ }^{19}{ }^{20}$ Secondly, to counteract the stimulatory effect of neurotensin on tumour cells, ${ }^{12}$ the long-term effect of neurotensin antagonists, such as SR $48692,{ }^{21}$ may be investigated.

1 Rosewicz S, Wiedenmann B. Pancreatic carcinoma. Lancet 1997;349:485-9.

2 Warshaw AL, Fernandes-Del Castillo C. Pancreatic carcinoma. $N$ Engl f Med 1992;326:455-64.

3 Krenning EP, Bakker WH, Breeman WAP, et al. Localisation of endocrine-related tumours with radioiodinated analogue of somatostatin. Lancet 1989;I:242-4.

4 Krenning EP, Kwekkeboom DJ, Pauwels S, et al. Somatostatin receptor scintigraphy. Nuclear Medicine Annual 1995; 1995:1-50.

5 Gibril F, Reynolds JC, Doppman JL, et al. Somatostatin receptor scintigraphy: its sensitivity compared with that of other imaging methods in detecting primary and metastatic gastrinomas. Ann Intern Med 1996;125:26-34.

6 Reubi JC, Schaer JC, Waser B, Mengod G. Expression and localization of somatostatin receptor SSTR1, SSTR2 and SSTR3 mRNAs in primary human tumors using in situ hybridization. Cancer Res 1994;54:3455-9.

7 John M, Meyerhof W, Richter D, et al. Positive somatostatin receptor scintigraphy correlates with the presence of somatostatin receptor subtype 2. Gut 1996;38:33-9.

8 Reubi JC, Horisberger U, Essed CE, et al. Absence of somatostatin receptors in human exocrine pancreatic adenocarcinomas. Gastroenterology 1988;95:760-3.

9 Buscail L, Saint-Laurent N, Chastre E, et al. Loss of sst2 somatostatin receptor gene expression in human pancreatic
and colorectal cancer. Cancer Res 1996;56:1823-7.

10 Reubi JC. Neuropeptide receptors in health and disease: the molecular basis for in vivo imaging. $f$ Nucl Med 1995;36:1825-35.

11 Shulkes A. Neurotensin. New York: Raven Press, 1994. 
12 Ishizuka J, Townsend CM, Thompson JC. Neurotensin regulates growth of human pancreatic cancer. Ann Surg regulates growth

13 Reubi JC, Kvols LK, Waser B, et al. Detection of somatostatin receptors in surgical and percutaneous needle biopsy samples of carcinoids and islet cell carcinomas. Cancer Res 1990;50:5969-77.

14 Moyse E, Rostène W, Vial M, et al. Distribution of neurotensin binding sites in rat brain: a light microscopic radioautographic study using monoiodo $\left({ }^{125}-\mathrm{I}\right) \mathrm{Tyr}^{3}-$ neurotensin. Neuroscience 1987;22:525-36.

15 Korc M, Friess H, Kobrin MS, et al. Growth factors in human pancreatic cancer: update on the role of the epidermal growth factor receptor. Digestive Surgery 1994;11:1479.

16 Löwenfels AB, Maisonneuve P, Cavallini G, et al. Pancreatitis and the risk of pancreatic cancer. $N$ Engl $f$ Med 1993;328:1433-7.
17 Tourwé D, Mertens J, Ceusters $M$, et al. The synthesis of metabolically stabilized peptides and their radiolabeling: new ( ${ }^{111}-$ In) -

18 Beaudet A, Mazella J, Nouel D, et al. Internalization and intracellular mobilization of neurotensin in neuronal cells. Biochem Pharmacol 1994;47:43-52.

9 Krenning EP, Valkema R, Kooij PPM, et al. Radionuclide therapy with (11-In-DTPA-D-Phe-1)-octreotide. Preliminary data of a phase 1 study. Reston, VA: Society of Nuclear Medicine, 1996.

20 Stolz B, Smith-Jones P, Weckbecker G, et al. Radiotherapy bearing rodents. 7 Nucl Med 1997:38

21 Gully D, Canton M, Goigegrain R, et al. Biochemical and pharmacological profile of a potent and selective nonpeptide antagonist of the neurotensin receptor. Proc Natl Acad Sci USA 1993;90:65-9. 